Acta Crystallographica Section C

Crystal Structure

Communications

ISSN 0108-2701

\section{Extensive hydrogen and halogen bonding, and absence of intra- molecular hydrogen bonding between alcohol and nitro groups in a series of endo-nitronorbornanol compounds}

\section{Andreas Lemmerer* and Joseph P. Michael}

Molecular Sciences Institute, School of Chemistry, University of the Witwatersrand, Johannesburg, PO Wits 2050, South Africa

Correspondence e-mail: andreas.lemmerer@wits.ac.za

Received 28 April 2011

Accepted 20 June 2011

Online 5 July 2011

The influence of the substituent at the C2 position on the hydrogen-bonding patterns is compared for a series of five related compounds, namely ( \pm )-3-exo,6-exo-dibromo-5-endohydroxy-3-endo-nitrobicyclo[2.2.1] heptane-2-exo-carbonitrile, $\mathrm{C}_{8} \mathrm{H}_{8} \mathrm{Br}_{2} \mathrm{~N}_{2} \mathrm{O}_{3}$, (II), ( \pm )-3-exo,6-exo-dibromo-6-endo-nitro-5exo-phenylbicyclo[2.2.1] heptan-2-endo-ol, $\mathrm{C}_{13} \mathrm{H}_{13} \mathrm{Br}_{2} \mathrm{NO}_{3}$, (III), ( \pm )-methyl 3-exo,6-exo-dibromo-5-endo-hydroxy-3-endo-nitrobicyclo[2.2.1] heptane-2-exo-carboxylate, $\mathrm{C}_{9} \mathrm{H}_{11} \mathrm{Br}_{2} \mathrm{NO}_{5}$, (IV), ( \pm -methyl 3-exo,6-exo-dibromo-7-diphenylmethylidene-5endo-hydroxy-3-endo-nitrobicyclo[2.2.1] heptane-2-exo-carboxylate, $\mathrm{C}_{22} \mathrm{H}_{19} \mathrm{Br}_{2} \mathrm{NO}_{5}$, (V), and ( \pm )-methyl 3-exo,6-exodibromo-5-endo-hydroxy-3-endo-nitro-7-oxabicyclo[2.2.1] heptane-2-exo-carboxylate, $\mathrm{C}_{8} \mathrm{H}_{9} \mathrm{Br}_{2} \mathrm{NO}_{6}$, (VI). The hydrogenbonding motif in all five compounds is a chain, formed by $\mathrm{O}-$ $\mathrm{H}$... O hydrogen bonds in (III), (IV), (V) and (VI), and by $\mathrm{O}-\mathrm{H} \cdots \mathrm{N}$ hydrogen bonds in (II). All compounds except (III) contain a number of $\mathrm{Br} \cdots \mathrm{Br}$ and $\mathrm{Br} \cdots \mathrm{O}$ halogen bonds that connect the chains to each other to form two-dimensional sheets or three-dimensional networks. None of the compounds features intramolecular hydrogen bonding between the alcohol and nitro functional groups, as was found in the related compound ( \pm )-methyl 3-exo,6-exo-dichloro-5-endohydroxy-3-endo-nitrobicyclo[2.2.1]heptane-2-exo-carboxylate, (I) [Boeyens, Denner \& Michael (1984b). J. Chem. Soc. Perkin Trans. 2, pp. 767-770]. The crystal structure of (V) exhibits whole-molecule disorder.

\section{Comment}

Although hydrogen bonding between hydroxy and nitro groups is not uncommon (Desiraju, 2002), intramolecular hydrogen bonding between these groups is largely confined to systems in which they find themselves in enforced proximity, as in 2-nitrophenols (Baitinger et al., 1964; Heintz et al., 2007;
Litwinienko et al., 2009). We have been interested in hydrogen bonding in nitronorbornanol systems for several years (Boeyens et al., 1984a; Michael et al., 1994). In particular, when both groups are constrained to occupy the endo cavity of the norbornane skeleton, the likelihood of intramolecular hydrogen bonding is high, as we have found, for example, in 3-exo,6-exo-dichloro-5-endo-hydroxy-3-endo-nitrobicyclo[2.2.1]heptane-2-exo-carbonitrile, (I) (Boeyens et al., 1984b). We previously determined the room-temperature crystal structure of the corresponding dibromo compound 3-exo,6-exo-dibromo-5-endo-hydroxy-3-endo-nitrobicyclo[2.2.1]heptane-2exo-carbonitrile, (II) (Blom et al., 1980), but owing to the limitations of the techniques available at the time, we were unable to locate $\mathrm{H}$ atoms and to establish unambiguously whether or not the hydrogen bonding was intramolecular. We report here a redetermination of the crystal structure of compound (II) at low temperature, as well as the structures of three analogous dibrominated endo-nitronorbornanols, (III)(V), and the related 7-oxanorbornanol, (VI), in order to elucidate their hydrogen-bonding patterns and to establish whether there is any intra- or intermolecular hydrogen bonding between the alcohol and nitro functionalities.<smiles>N#CC1CC2C(Cl)C(O)C1C2(Cl)[N+](=O)[O-]</smiles>

(I)<smiles>O=[N+]([O-])C1(Br)C(O)C2CC(Br)C1C2c1ccccc1</smiles>
(III)<smiles>CC(=O)C1CC(=C(c2ccccc2)c2ccccc2)C(Br)C1C(=O)O</smiles>

(V)

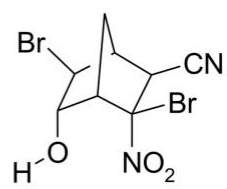

(II)<smiles>COC(OC)C1CC2CC1C(Br)C2(O)[N+](=O)[O-]</smiles><smiles>COC1C(Br)C2OC1C([N+](=O)[O-])C2OO</smiles>

(VI)
The distances and angles within the five compounds reported (Fig. 1) are generally as expected (Allen et al., 1987). In all five structures, hydrogen bonds play a part in controlling the supramolecular assembly of the molecules (Desiraju, , 2002). All five compounds contain an alcohol group and a number of good hydrogen-bonding acceptor functional groups including nitro, ester and ether units as well as $\mathrm{Br}$ atoms. Furthermore, a number of halogen-type $\mathrm{C}-\mathrm{Br} \cdots A(A=\mathrm{Br}$ or $\mathrm{O}$; Metrangelo et al., 2005) interactions are also present (Fig. 2).

Compound (II) crystallizes in the polar space group $C c$. The $\mathrm{O} 1-\mathrm{H} 1 \cdots \mathrm{N} 2$ hydrogen bond forms a $C(8)$ (Bernstein et al., 1995) chain along the [010] direction. Adjacent chains of this type are connected by a $\mathrm{Br} 2 \cdots \mathrm{O} 2$ halogen interaction along 


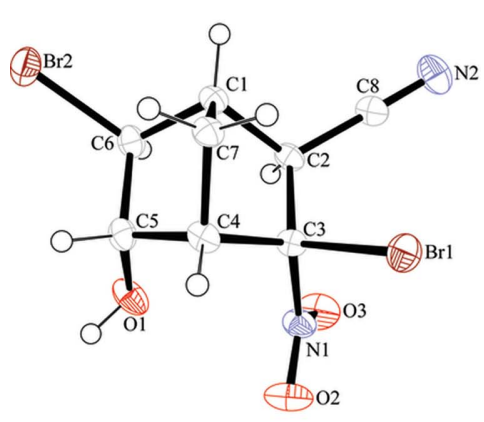

(a)

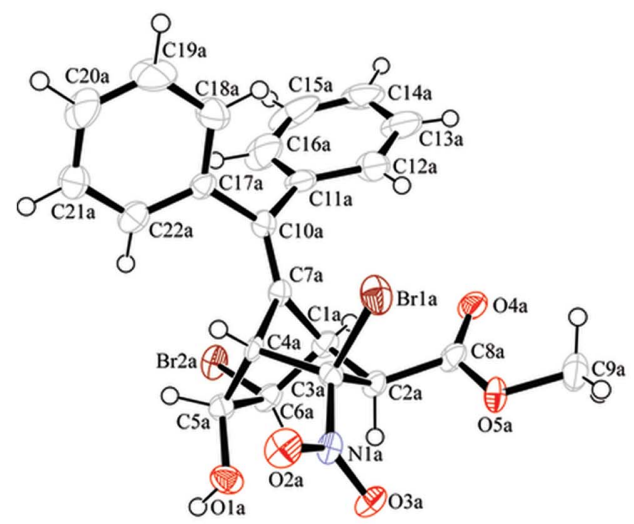

$(d)$

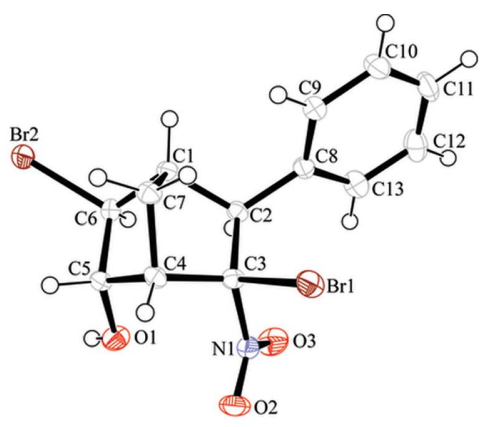

(b)

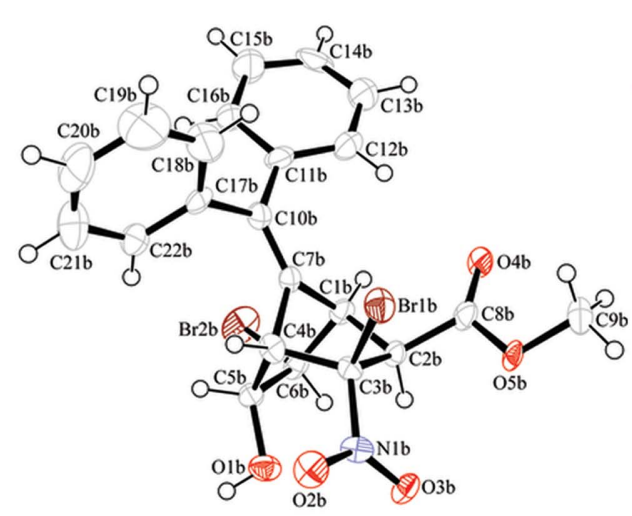

(e)

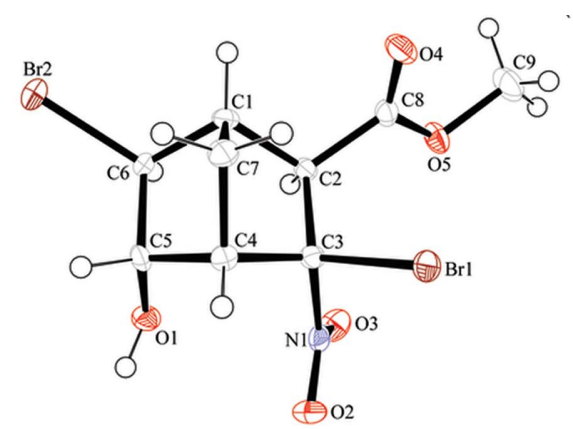

(c)

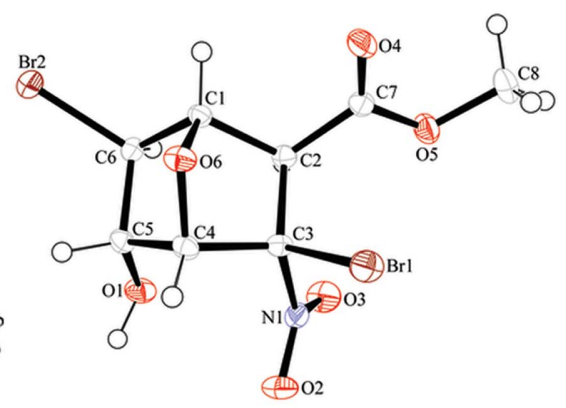

$(f)$

Figure 1

The molecular structures and atom-labelling schemes for $(a)(\mathrm{II}),(b)(\mathrm{III}),(c)(\mathrm{IV}),(d)$ molecule $A$ of $(\mathrm{V}),(e)$ molecule $B$ of $(\mathrm{V})$ and $(f)$ (VI). Displacement ellipsoids are drawn at the $50 \%$ probability level and $\mathrm{H}$ atoms are drawn as small spheres of arbitrary radii.

the [001] direction (Fig. 3) and by a Br1 . Br2 halogen interaction (Table 6) along the [100] direction to form a threedimensional network.

In compound (III), the $\mathrm{O} 1-\mathrm{H} 1 \cdots \mathrm{O} 2$ hydrogen bond forms $C(7)$ chains along the [010] direction, containing molecules related by the twofold screw axis along (0.5, y, 0.75) (Fig. 4). Compound (III) has no short $\mathrm{Br} \cdot \mathrm{Br}$ contacts and does not form a higher-dimensional network.

In the crystal structure of compound (IV), $C(8)$ chains are formed along the [1] 0 ] direction, utilizing the $\mathrm{O} 1-\mathrm{H} 1 \cdots \mathrm{O} 4$ hydrogen bond (Fig. 5a). Adjacent chains of this type are connected to form a three-dimensional network by $\mathrm{Br} 2 \cdots \mathrm{Br} 2$ interactions along the [001] direction and by Br1 ‥O1 interactions along the [010] direction (Table 6, and Figs. $5 a$ and $5 b$ ).

The entire molecule of compound $(\mathrm{V})$ is disordered over two sets of atomic positions and the two parts, labelled $A$ and $B$ (Fig. 1), have equal site-occupancy factors. The only substantial conformational difference between the two

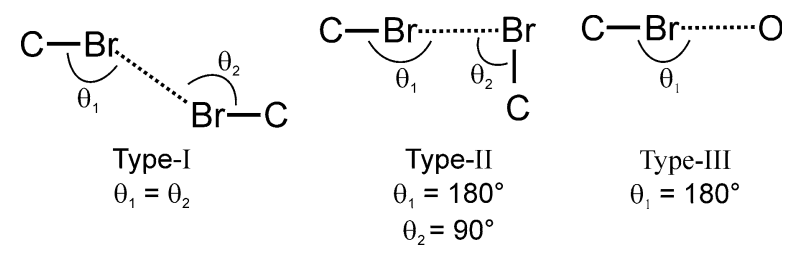

Figure 2

The three types of halogen bonding observed in this study of nitronorbornanols. disorder components is the orientations of the aromatic rings relative to the nitronorbornanol unit. Molecule $A$ has torsion angles of $-46.9(15)^{\circ}(\mathrm{C} 7 A-\mathrm{C} 10 A-\mathrm{C} 17 A-\mathrm{C} 22 A)$ and $120.9(12)^{\circ}(\mathrm{C} 7 A-\mathrm{C} 10 A-\mathrm{C} 11 A-\mathrm{C} 16 A)$, as compared to angles of $-61.3(14)^{\circ}(\mathrm{C} 7 B-\mathrm{C} 10 B-\mathrm{C} 17 B-\mathrm{C} 22 B)$ and $139.4(12)^{\circ}(\mathrm{C} 7 B-\mathrm{C} 10 B-\mathrm{C} 11 B-\mathrm{C} 16 B)$ in molecule $B$. Nonetheless, the intermolecular hydrogen and halogen bonding is similar between the two molecules (Tables 4 and 6). The $\mathrm{O} 1 A-\mathrm{H} 1 A \cdots \mathrm{O} 3 A$ hydrogen bond in molecule $A$ forms $C(7)$ chains from alcohol atom $\mathrm{O} 1 A$ to nitro atom $\mathrm{O} 3 A$. The chains run along the [010] direction (Fig. 6), generated by the

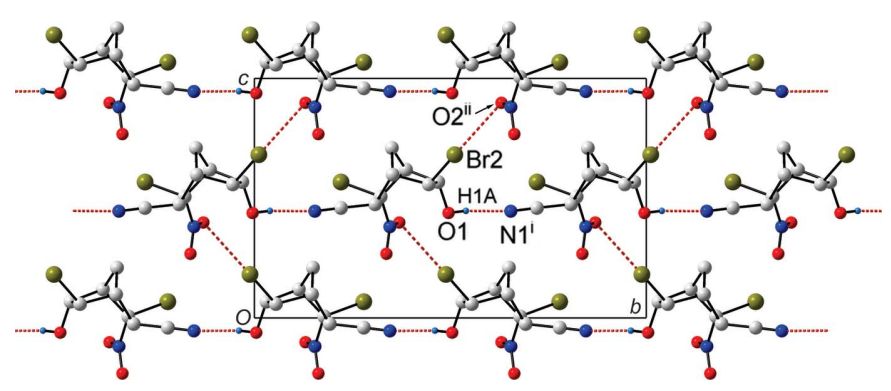

Figure 3

The $C(8)$ hydrogen-bonded chain of (II), showing the $\mathrm{Br} \cdots \mathrm{O}$ halogenbonded interactions along the [001] direction. The $\mathrm{Br} \cdots \mathrm{Br}$ halogen bonds along the [100] direction are not shown. Atoms marked with the superscripts ' $\mathrm{i}$ ' and 'ii' are at the symmetry positions $\left(x-\frac{1}{2}, y+\frac{1}{2}, z\right)$ and $\left(x+1,-y+1, z+\frac{1}{2}\right)$, respectively. $\mathrm{H}$ atoms not involved in hydrogenbonding interactions have been omitted for clarity. 


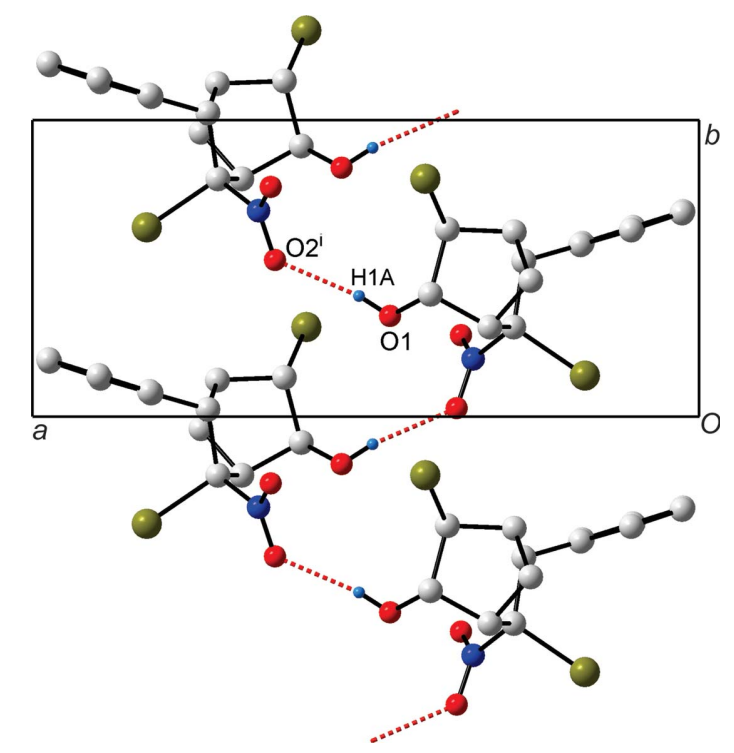

Figure 4

The $C(7)$ hydrogen-bonded chain of (III). Atoms marked with the superscript ' $\mathrm{i}$ ' are at the symmetry position $\left(-x+1, y+\frac{1}{2},-z+\frac{3}{2}\right)$. $\mathrm{H}$ atoms not involved in hydrogen-bonding interactions have been omitted for clarity.

twofold screw axis in the space group $P 2_{1} / c$. The molecules within the chains are further connected by $\mathrm{Br} 2 A \cdots \mathrm{O} 3 A$ halogen bonds (Table 6 and Fig. 6). (V) contains no $\mathrm{Br} \cdots \mathrm{Br}$ halogen bonds. The hydrogen bonding of molecule $B$ is not shown in Fig. 6.

In the crystal structure of compound (VI), the O1$\mathrm{H} 1 \cdots \mathrm{O} 4$ hydrogen bond forms $C(8)$ chains along the [101] direction (Fig. 7a). Adjacent hydrogen-bonded chains are connected by $\mathrm{Br} 1 \cdots \mathrm{O} 1$ interactions along the [100] direction to form sheets (Fig. 7a). Two adjacent sheets are then connected by $\mathrm{Br} 2 \cdots \mathrm{Br} 2$ halogen bonds along [010] (Table 6) to form bilayers of sheets (Fig. $7 b$ ).

Compound (II), which is the dibromo analogue of (I), does not contain an intramolecular $\mathrm{O}-\mathrm{H} \cdots \mathrm{O}$ (nitro) hydrogen bond as observed in (I). Instead, it forms a $C(8)$ hydrogenbonded chain with the nitrile $\mathrm{N}$ atom as acceptor on a neighbouring molecule. Nonetheless, the $\mathrm{O}$ atoms of the nitro group are utilized in intermolecular interactions, in this case halogen bonding with the $\mathrm{Br}$ atoms to form two-dimensional sheets which are further linked into a three-dimensional network via $\mathrm{Br} \cdots \mathrm{Br}$ interactions. Compound (III) has the nitrile group replaced by a phenyl group, and this seems to have an influence on the lack of any halogen bonding observed in (III) because of the steric increase of the phenyl group next to one of the $\mathrm{Br}$ atoms. The absence of any good hydrogen-bonding acceptor at the 2-position leaves only the nitro group or the alcohol $\mathrm{O}$ atom as candidates and, indeed, in (III), there is an intermolecular $\mathrm{O}-\mathrm{H} \cdots \mathrm{O}$ (nitro) hydrogen bond forming $C(7)$ chains. Similar chains are formed by $(\mathrm{V})$, which at the same time uses the second $\mathrm{O}$ atom of the nitro group in halogen bonding to strengthen the chain motif. Compounds (IV) and (VI) have the same intermolecular hydrogen bonding from the alcohol to the ester carbonyl
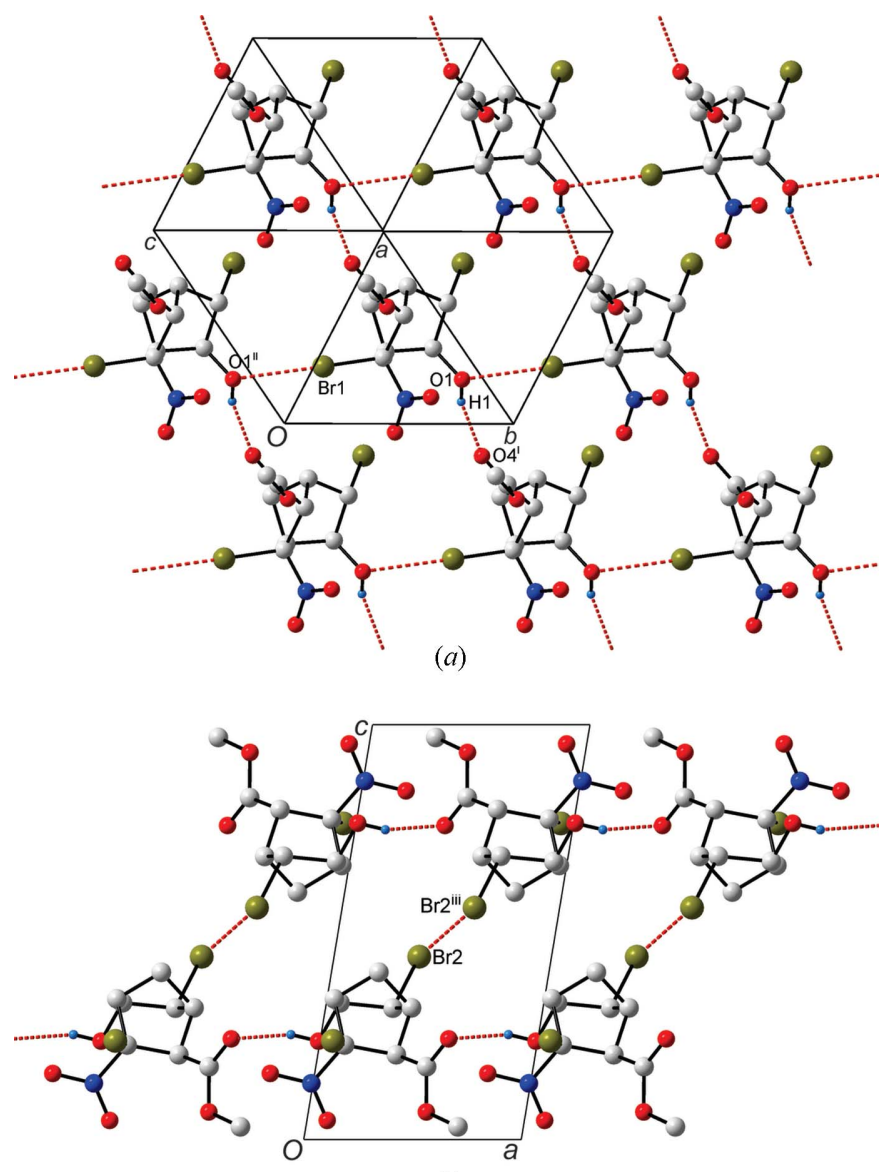

(b)

Figure 5

(a) The $C(8)$ hydrogen-bonded chain of (IV), as well as the $\mathrm{Br} \cdots \mathrm{O}$ halogen bonds forming a two-dimensional sheet. (b) The sheets are then connected into a three-dimensional network by $\mathrm{Br} \cdots \mathrm{Br}$ halogen bonds. Atoms marked with the superscripts ' $i$ ', 'ii' and 'iii' are at the symmetry positions $(x-1, y+1, z),(x, y-1, z)$ and $(-x+1,-y+2,-z+1)$, respectively. $\mathrm{H}$ atoms not involved in hydrogen-bonding interactions have been omitted for clarity.

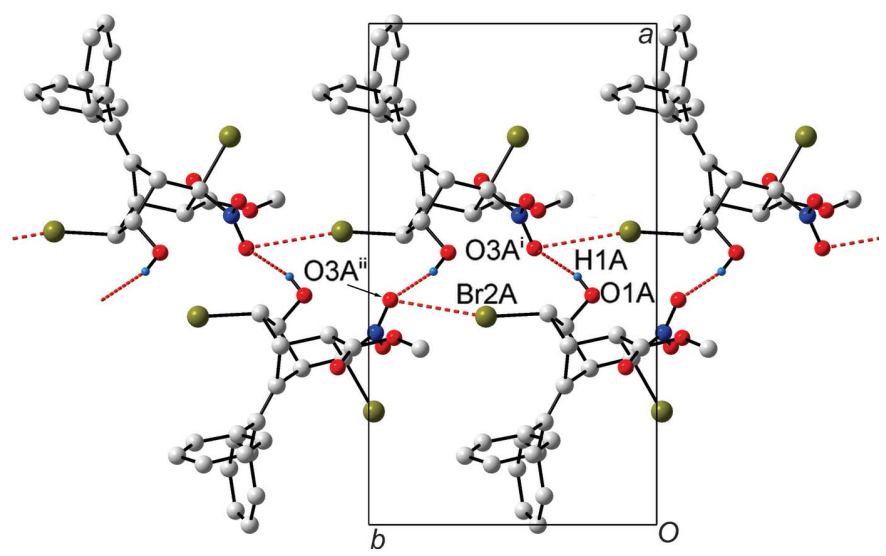

Figure 6

The $C(7)$ hydrogen-bonded chain of $(\mathrm{V})$. Note how the halogen bonding connects every second molecule involved in hydrogen-bonded interactions within the chain (by translation only). Only the hydrogen bonding of molecule $A$ is shown. Molecule $B$ has similar interactions but is not shown in the figure. Atoms marked with the superscripts ' $\mathrm{i}$ ' and 'ii' are at the symmetry positions $\left(-x+1, y+\frac{1}{2},-z+\frac{1}{2}\right)$ and $(x, y+1, z)$, respectively. $\mathrm{H}$ atoms not involved in hydrogen-bonding interactions have been omitted for clarity. 


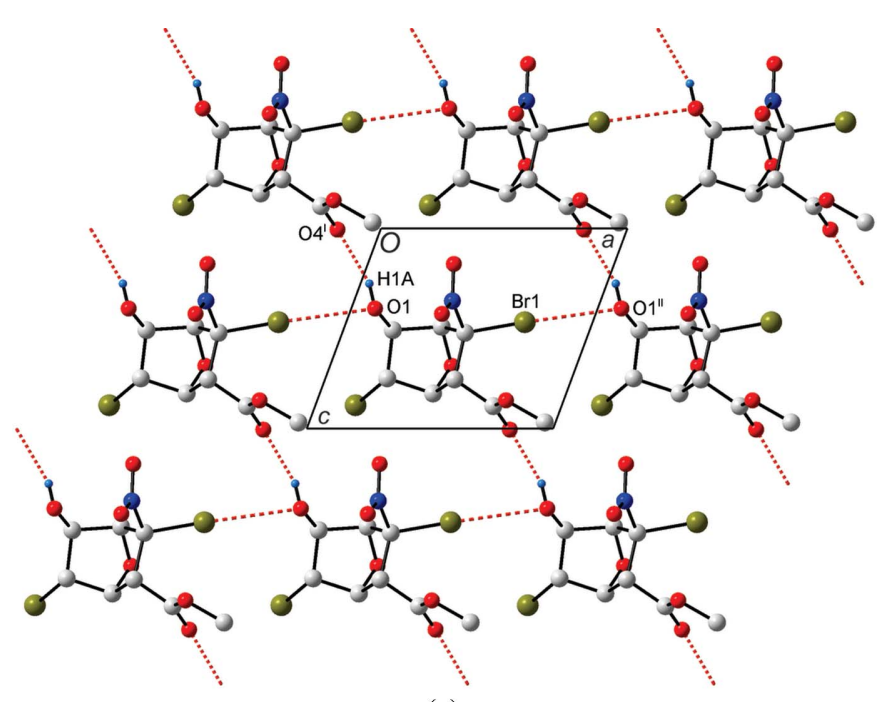

(a)

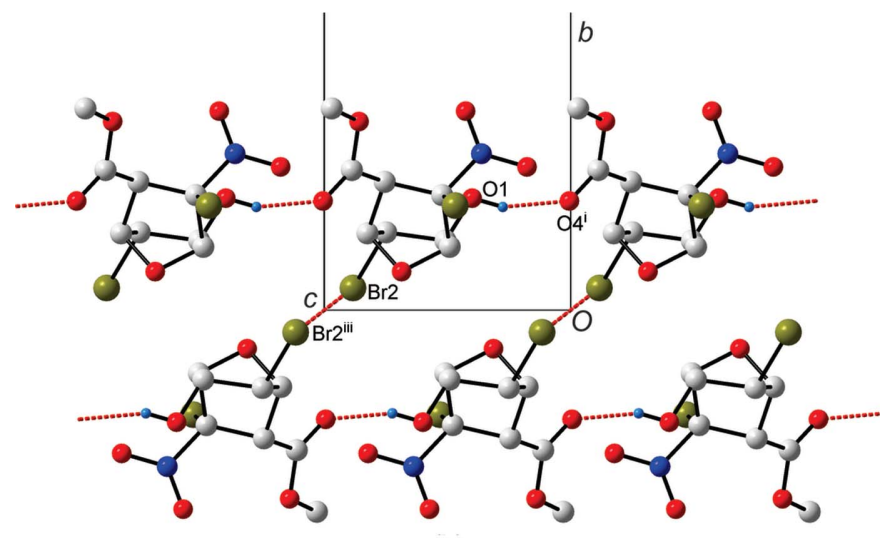

(b)

Figure 7

(a) The $C(8)$ hydrogen-bonded chains of (VI) connected by $\mathrm{Br} \cdots \mathrm{O}$ halogen bonds to form two-dimensional sheets. $(b)$ The sheets form bilayers through further $\mathrm{Br} \cdots \mathrm{Br}$ halogen bonding. Atoms marked with the superscripts ' $\mathrm{i}$ ', 'ii' and 'iii' are at the symmetry positions $(x-1, y$, $z-1),(x+1, y, z)$ and $(-x+2,-y,-z+2)$, respectively. $\mathrm{H}$ atoms not involved in hydrogen-bonding interactions have been omitted for clarity.

group, and similar packing of the chains into larger architectures. (IV) has chains connected in three dimensions by the halogen-bond interactions, whereas (VI) has bilayers of hydrogen-bonded sheets using similar $\mathrm{Br} \cdots \mathrm{Br}$ and $\mathrm{Br} \cdots \mathrm{O}$ interactions. The halogen bonds observed in these compounds all have $X \cdots A$ distances less than the van der Waals radii sum (3.70 $\AA$ for $\mathrm{Br} \cdots \mathrm{Br}$ contacts and $3.37 \AA$ for $\mathrm{Br} \cdots \mathrm{O}$ contacts).

\section{Experimental}

The syntheses and spectroscopic characterization of the five compounds (II)-(VI) by bromination of the corresponding endonitronorbonenes have been reported previously (Michael et al., 1991). In these syntheses, transannular neighbouring group participation by the nitro group during bromination of the alkene bond is responsible for the introduction of the endo-hydroxy group in a regiospecific and totally stereoselective manner. Crystals of (II) were grown from methanol, (III) from benzene, (IV) from benzene, (V) from ethyl acetate/hexane $(1: 1 \mathrm{v} / \mathrm{v})$ and (VI) from acetone, all by slow evaporation.

\section{Compound (II)}

Crystal data

$\mathrm{C}_{8} \mathrm{H}_{8} \mathrm{Br}_{2} \mathrm{~N}_{2} \mathrm{O}_{3}$

$M_{r}=339.98$

Monoclinic, $C c$

$a=6.6517(8) \AA$

$b=16.084(2) \AA$

$c=9.8254(14) \AA$

$\beta=91.825(6)^{\circ}$

\section{Data collection}

Bruker SMART 1K CCD areadetector diffractometer

Absorption correction: integration (XPREP; Bruker, 1999)

$T_{\min }=0.075, T_{\max }=0.301$

\section{Refinement}

$R\left[F^{2}>2 \sigma\left(F^{2}\right)\right]=0.045$

$w R\left(F^{2}\right)=0.116$

$S=1.04$

2038 reflections

139 parameters

2 restraints

$\mathrm{H}$ atoms treated by a mixture of independent and constrained refinement

\section{Compound (III)}

Crystal data

$\mathrm{C}_{13} \mathrm{H}_{13} \mathrm{Br}_{2} \mathrm{NO}_{3}$

$M_{r}=391.06$

Monoclinic, $P 2_{1} / c$

$a=15.945(2) \mathrm{A}$

$b=6.7578(10) \AA$

$c=13.194(2) \AA$

$\beta=107.655(9)^{\circ}$

\section{Data collection}

Bruker SMART 1K CCD areadetector diffractometer

Absorption correction: integration (XPREP; Bruker, 1999)

$$
T_{\min }=0.110, T_{\max }=0.467
$$

\section{Refinement}

$R\left[F^{2}>2 \sigma\left(F^{2}\right)\right]=0.022$

$w R\left(F^{2}\right)=0.052$

$S=1.04$

3256 reflections

175 parameters

\section{Compound (IV)}

\section{Crystal data}

$\mathrm{C}_{9} \mathrm{H}_{11} \mathrm{Br}_{2} \mathrm{NO}_{5}$

$M_{r}=373.01$

Triclinic, $P \overline{1}$

$a=6.7221$ (2) $\AA$

$b=7.7353(3) \AA$

$c=12.1546$ (5) $\AA$

$\alpha=88.296$ (3)

$\beta=80.595(3)^{\circ}$
$V=1050.6(2) \AA^{3}$

$Z=4$

Mo $K \alpha$ radiation

$\mu=7.70 \mathrm{~mm}^{-1}$

$T=173 \mathrm{~K}$

$0.6 \times 0.2 \times 0.2 \mathrm{~mm}$

3346 measured reflections 2038 independent reflections 1945 reflections with $I>2 \sigma(I)$ $R_{\text {int }}=0.067$

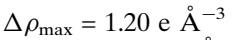

$\Delta \rho_{\min }=-0.94 \mathrm{e}^{-3}$

Absolute structure: Flack (1983),

765 Friedel pairs

Flack parameter: 0.003 (19)

$$
\begin{aligned}
& V=1354.7(4) \AA^{3} \\
& Z=4 \\
& \text { Mo } K \alpha \text { radiation } \\
& \mu=5.99 \mathrm{~mm}^{-1} \\
& T=173 \mathrm{~K} \\
& 0.4 \times 0.3 \times 0.14 \mathrm{~mm}
\end{aligned}
$$

18725 measured reflections 3256 independent reflections 2786 reflections with $I>2 \sigma(I)$ $R_{\text {int }}=0.042$

$\mathrm{H}$ atoms treated by a mixture of independent and constrained refinement $\Delta \rho_{\max }=0.34{\mathrm{e} \AA^{-3}}^{-3}$ $\Delta \rho_{\min }=-0.64$ e $\AA^{-3}$ 


\section{Data collection}

Bruker SMART 1K CCD areadetector diffractometer

Absorption correction: integration (XPREP; Bruker, 1999)

$T_{\text {min }}=0.318, T_{\max }=0.770$

\section{Refinement}

$R\left[F^{2}>2 \sigma\left(F^{2}\right)\right]=0.039$

$w R\left(F^{2}\right)=0.07$

$S=0.96$

2805 reflections

\section{Compound (V)}

Crystal data

$\mathrm{C}_{22} \mathrm{H}_{19} \mathrm{Br}_{2} \mathrm{NO}_{5}$

$M_{r}=537.2$

Monoclinic, $P 2_{1} / c$

$a=15.8724(8) \AA$

$b=9.0341(4) \AA$

$c=15.0064$ (7) $\AA$

$\beta=98.219(2)^{\circ}$

\section{Data collection}

Bruker SMART 1K CCD areadetector diffractometer

Absorption correction: integration

(XPREP; Bruker, 1999)

$T_{\min }=0.509, T_{\max }=0.817$

\section{Refinement}

$R\left[F^{2}>2 \sigma\left(F^{2}\right)\right]=0.033$

$w R\left(F^{2}\right)=0.057$

$S=0.82$

5119 reflections

467 parameters

\section{Compound (VI)}

Crystal data

$\mathrm{C}_{8} \mathrm{H}_{9} \mathrm{Br}_{2} \mathrm{NO}_{6}$

$M_{r}=374.98$

Monoclinic, $P 2_{1} / c$

$a=7.8071$ (13) А

$b=22.760(4) \AA$

$c=6.7673(10) \AA$

$\beta=110.32(1)^{\circ}$

Data collection

Bruker SMART 1K CCD areadetector diffractometer

Absorption correction: integration (XPREP; Bruker, 1999)

$T_{\min }=0.092, T_{\max }=0.290$

\section{Refinement}

$R\left[F^{2}>2 \sigma\left(F^{2}\right)\right]=0.032$

$w R\left(F^{2}\right)=0.076$

$S=1.22$

2715 reflections

158 parameters
7104 measured reflections 2805 independent reflections 2244 reflections with $I>2 \sigma(I)$ $R_{\text {int }}=0.083$

155 parameters

$\mathrm{H}$-atom parameters constrained

$\Delta \rho_{\max }=1.44{\mathrm{e} \AA^{-3}}^{-3}$

$\Delta \rho_{\min }=-1.41{\mathrm{e} \AA^{-3}}^{-3}$

$$
\begin{aligned}
& V=2129.71(17) \AA^{3} \\
& Z=4 \\
& \text { Mo } K \alpha \text { radiation } \\
& \mu=3.84 \mathrm{~mm}^{-1} \\
& T=173 \mathrm{~K} \\
& 0.3 \times 0.1 \times 0.06 \mathrm{~mm}
\end{aligned}
$$

17671 measured reflections 5119 independent reflections 3059 reflections with $I>2 \sigma(I)$

$R_{\text {int }}=0.078$

83 restraints

$\mathrm{H}$-atom parameters constrained $\Delta \rho_{\max }=0.45{\mathrm{e} \AA^{-3}}^{-3}$

$\Delta \rho_{\min }=-0.43{\mathrm{e} \AA^{-3}}^{-3}$

$$
\begin{aligned}
& V=1127.7(3) \AA^{3} \\
& Z=4 \\
& \text { Mo } K \alpha \text { radiation } \\
& \mu=7.21 \mathrm{~mm}^{-1} \\
& T=173 \mathrm{~K} \\
& 0.42 \times 0.4 \times 0.2 \mathrm{~mm}
\end{aligned}
$$

12168 measured reflections 2715 independent reflections 2453 reflections with $I>2 \sigma(I)$ $R_{\text {int }}=0.085$

\footnotetext{
$\mathrm{H}$ atoms treated by a mixture of independent and constrained refinement

$\Delta \rho_{\max }=0.47{\mathrm{e} \AA^{-3}}^{-3}$

$\Delta \rho_{\min }=-0.92{\mathrm{e} \AA^{-3}}^{-3}$
}

The whole-molecule disorder of (V) was modelled by finding alternative positions for all the atoms in the molecule. The corresponding bonded distance and the one-angle nonbonded distances in

Table 1

Hydrogen-bond geometry $\left(\AA,^{\circ}\right)$ for (II).

\begin{tabular}{lllll}
\hline$D-\mathrm{H} \cdots A$ & $D-\mathrm{H}$ & $\mathrm{H} \cdots A$ & $D \cdots A$ & $D-\mathrm{H} \cdots A$ \\
\hline $\mathrm{O} 1-\mathrm{H} 1 \cdots \mathrm{N} 22^{\mathrm{i}}$ & $0.86(12)$ & $2.01(12)$ & $2.858(8)$ & $169(10)$ \\
\hline Symmetry code: (i) $x-\frac{1}{2}, y+\frac{1}{2}, z$ & &
\end{tabular}

Symmetry code: (i) $x-\frac{1}{2}, y+\frac{1}{2}, z$.

Table 2

Hydrogen-bond geometry $\left(\AA,^{\circ}\right)$ for (III).

\begin{tabular}{lcccc}
\hline$D-\mathrm{H} \cdots A$ & $D-\mathrm{H}$ & $\mathrm{H} \cdots A$ & $D \cdots A$ & $D-\mathrm{H} \cdots A$ \\
\hline $\mathrm{O} 1-\mathrm{H} 1 \cdots \mathrm{O} 2^{\mathrm{i}}$ & $0.76(3)$ & $2.17(3)$ & $2.927(2)$ & $171(3)$ \\
\hline Symmetry code: $(\mathrm{i})-x+1, y+\frac{1}{2},-z+\frac{3}{2}$.
\end{tabular}

Table 3

Hydrogen-bond geometry $\left(\AA,^{\circ}\right)$ for (IV).

\begin{tabular}{lllll}
\hline$D-\mathrm{H} \cdots A$ & $D-\mathrm{H}$ & $\mathrm{H} \cdots A$ & $D \cdots A$ & $D-\mathrm{H} \cdots A$ \\
\hline $\mathrm{O} 1-\mathrm{H} 1 \cdots \mathrm{O} 4^{\mathrm{i}}$ & 0.84 & 1.96 & $2.752(3)$ & 157 \\
\hline
\end{tabular}

Symmetry code: (i) $x-1, y+1, z$.

Table 4

Hydrogen-bond geometry $\left(\AA,^{\circ}\right)$ for $(\mathrm{V})$.

\begin{tabular}{lllll}
\hline$D-\mathrm{H} \cdots A$ & $D-\mathrm{H}$ & $\mathrm{H} \cdots A$ & $D \cdots A$ & $D-\mathrm{H} \cdots A$ \\
\hline $\mathrm{O} 1 A-\mathrm{H} 1 A \cdots \mathrm{O} 3 A^{\mathrm{i}}$ & 0.84 & 2.24 & $3.03(2)$ & 157 \\
$\mathrm{O} 1 B-\mathrm{H} 1 B \cdots \mathrm{O} 3 B^{\mathrm{i}}$ & 0.84 & 2.14 & $2.90(3)$ & 151 \\
\hline
\end{tabular}

Symmetry code: (i) $-x+1, y+\frac{1}{2},-z+\frac{1}{2}$.

the two disorder components were restrained to have the same values, subject to s.u. values of 0.005 and $0.01 \AA$, respectively. The atomic displacement parameters were restrained to be equal for each of the atom pairs $\mathrm{C} 1 A / \mathrm{C} 1 B, \mathrm{C} 2 A / \mathrm{C} 2 B, \mathrm{C} 3 A / \mathrm{C} 3 B, \mathrm{C} 5 A / \mathrm{C} 5 B, \mathrm{O} 1 A$ / $\mathrm{O} 1 B, \mathrm{C} 6 A / \mathrm{C} 6 B, \mathrm{C} 7 A / \mathrm{C} 7 B, \mathrm{C} 8 A / \mathrm{C} 8 B, \mathrm{C} 9 A / \mathrm{C} 9 B, \mathrm{O} 2 A / \mathrm{O} 2 B, \mathrm{O} 3 A /$ $\mathrm{O} 3 B, \mathrm{C} 10 A / \mathrm{C} 10 B$ and $\mathrm{C} 11 A / \mathrm{C} 11 B$. Refinement of the site occupancies gave values of 0.501 (8) and 0.499 (8): the occupancies were thereafter both fixed at 0.50 . For all compounds, all $\mathrm{C}-\mathrm{H}$ atoms were refined using a riding model, with distances of 0.95 (aromatic), 1.00 (aliphatic $\mathrm{CH}), 0.99\left(\mathrm{CH}_{2}\right)$ and $0.98 \AA\left(\mathrm{CH}_{3}\right)$, and with $U_{\text {iso }}(\mathrm{H})=$ $1.2 U_{\text {eq }}(\mathrm{C})$ or $1.5 U_{\text {eq }}(\mathrm{C}) . \mathrm{H}$ atoms on $\mathrm{O}$ atoms which are involved in hydrogen-bonding interactions were located in difference maps for all compounds except (IV) and (V) (which were refined using a riding model) and their positions allowed to refine freely, with $U_{\text {iso }}(\mathrm{H})=$ $1.5 U_{\text {eq }}(\mathrm{O})$ for all compounds. The value of the Flack $x$ parameter (Flack, 1983) for (II), viz. 0.003 (19), confirms the correct orientation of the structure with respect to the two polar-axis directions in the space group $C c$.

For all compounds, data collection: SMART-NT (Bruker, 1998); cell refinement: SAINT-Plus (Bruker, 1999); data reduction: SAINTPlus; program(s) used to solve structure: SHELXS97 (Sheldrick, 2008); program(s) used to refine structure: SHELXL97 (Sheldrick, 2008); molecular graphics: ORTEP-3 for Windows (Farrugia, 1997) and DIAMOND (Brandenburg, 1999); software used to prepare material for publication: WinGX (Farrugia, 1999) and PLATON (Spek, 2009).

This material is based upon work supported financially by the National Research Foundation, Pretoria (GUN 65559). Any opinions, findings and conclusions or recommendations 
Table 5

Hydrogen-bond geometry $\left(\AA,^{\circ}\right)$ for (VI).

\begin{tabular}{lllll}
\hline$D-\mathrm{H} \cdots A$ & $D-\mathrm{H}$ & $\mathrm{H} \cdots A$ & $D \cdots A$ & $D-\mathrm{H} \cdots A$ \\
\hline $\mathrm{O} 1-\mathrm{H} 1 \cdots \mathrm{O} 4^{\mathrm{i}}$ & $0.89(4)$ & $1.94(4)$ & $2.774(3)$ & $156(4)$ \\
\hline
\end{tabular}

Symmetry code: (i) $x-1, y, z-1$.

expressed in this material are those of the authors and therefore the NRF does not accept any liability in regard thereto. This work was also supported by the University of the Witwatersrand, which is thanked for providing the infrastructure required to do this work.

Supplementary data for this paper are available from the IUCr electronic archives (Reference: GD3390). Services for accessing these data are described at the back of the journal.

\section{References}

Allen, F. H., Kennard, O., Watson, D. G., Brammer, L., Orpen, A. G. \& Taylor, R. (1987). J. Chem. Soc. Perkin Trans. 2, pp. S1-19.

Baitinger, W. F., Schleyer, P. R., Murty, T. S. S. R. \& Robinson, L. (1964). Tetrahedron, 20, 1635-1647.

Bernstein, J., Davis, R. E., Shimoni, L. \& Chang, N. L. (1995). Angew. Chem. Int. Ed. Engl. 34, 1555-1573.

Blom, N. F., Edwards, D. M. F., Field, J. S. \& Michael, J. P. (1980). J. Chem. Soc. Chem. Commun. pp. 1240-1241.

Boeyens, J. C. A., Denner, L. \& Michael, J. P. (1984a). J. Chem. Soc. Perkin Trans. 2, pp. 1569-1573.

Boeyens, J. C. A., Denner, L. \& Michael, J. P. (1984b). J. Chem. Soc. Perkin Trans. 2, pp. 767-770.

Brandenburg, K. (1999). DIAMOND. Crystal Impact GbR, Bonn, Germany.
Table 6

$\mathrm{Br} \cdots \mathrm{Br}$ and $\mathrm{Br} \cdots \mathrm{O}$ geometries in four of the five title compounds $\left(\AA{ }^{\circ},{ }^{\circ}\right.$.

\begin{tabular}{llllll}
\hline Compound & Interaction & $X \cdots X$ & $\theta_{1}$ & $\theta_{2}$ & Type \\
\hline (II) & $\mathrm{C} 3-\mathrm{Br} 1 \cdots \mathrm{Br}^{\mathrm{i}} 2^{\mathrm{i}}$ & $3.663(2)$ & 138 & 99 & II \\
& $\mathrm{C} 6-\mathrm{Br} 2 \cdots \mathrm{O}^{\mathrm{ii}}$ & $3.205(2)$ & 155 & & III \\
(IV) & $\mathrm{C} 6-\mathrm{Br} 2 \cdots \mathrm{Br}^{\mathrm{iii}}$ & $3.453(4)$ & 155 & 155 & I \\
& $\mathrm{C} 3-\mathrm{Br} 1 \cdots 1^{\mathrm{iv}}$ & $3.017(3)$ & 176 & & III \\
(V) & $\mathrm{C} 6 A-\mathrm{Br} 2 A \cdots \mathrm{O} 3 A^{\mathrm{v}}$ & $3.159(2)$ & 158 & & III \\
& $\mathrm{C} 6 B-\mathrm{Br} 2 B \cdots \mathrm{O} 3 B^{\mathrm{v}}$ & $3.258(2)$ & 152 & & III \\
(VI) & $\mathrm{C} 6-\mathrm{Br} 2 \cdots \mathrm{Br}^{\mathrm{vi}}$ & $3.608(10)$ & 149 & 149 & I \\
& $\mathrm{C} 3-\mathrm{Br} 1 \cdots 1^{\mathrm{vii}}$ & $3.097(5)$ & 168 & & III \\
\hline
\end{tabular}

Symmetry codes: (i) $x-\frac{1}{2}, y-\frac{1}{2}, z$; (ii) $x+1,-y+1, z+\frac{1}{2}$; (iii) $-x+1,-y+2,-z+1$; (iv) $x, y-1, z$; (v) $x, y+1, z$; (vi) $-x+2,-y,-z+2$; (vii) $x+1, y, z$.

Bruker (1998). SMART-NT. Bruker AXS Inc., Madison, Wisconsin, USA. Bruker (1999). SAINT-Plus (including XPREP). Version 6.02. Bruker AXS Inc., Madison, Wisconsin, USA.

Desiraju, G. R. (1996). Acc. Chem. Res. 29, 441-449.

Desiraju, G. R. (2002). Acc. Chem. Res. 35, 565-573.

Farrugia, L. J. (1997). J. Appl. Cryst. 30, 565.

Farrugia, L. J. (1999). J. Appl. Cryst. 32, 837-838.

Flack, H. D. (1983). Acta Cryst. A39, 876-881.

Heintz, A., Kapteina, S. \& Verevkin, S. P. (2007). J. Phys. Chem. A, 111, 65526562.

Litwinienko, G., DiLabio, G. A., Mulder, P., Korth, H.-G. \& Ingold, K. U. (2009). J. Phys. Chem. A, 113, 6275-6288.

Metrangelo, P., Neukirch, H., Pilati, T. \& Resnati, G. (2005). Acc. Chem. Res. 38, 386-395.

Michael, J. P., Billing, D. G. \& Maqutu, T. L. (1994). J. Chem. Crystallogr. 24, 311-314.

Michael, J. P., Blom, N. F. \& Glintenkamp, L. A. (1991). J. Chem. Soc. Perkin Trans. 1, pp. 1855-1862.

Sheldrick, G. M. (2008). Acta Cryst. A64, 112-122.

Spek, A. L. (2009). Acta Cryst. D65, 148-155. 